\title{
A ATUAÇÃO DO BRASIL NA AMÉRICA LATINA: UMA BREVE REFLEXÃO SOBRE O SUBIMPERIALISMO BRASILERIO
}

Bernard Teixeira Coutinho*

Guilherme Pereira do Carmo**

Resumo: Neste artigo, pretendemos levantar algumas proposições conceituais que nos ajudem a entender a atuação do Brasil na América Latina e, tão logo, permitir iniciar um debate sobre a política externa brasileira contemporânea e suas aplicações práticas na geopolítica inserida na economia-mundo. Para tanto, pretendemos explicitar o conceito de multiterritorialidade e apontar os contornos da tese do subimperialismo brasileiro de Ruy Mauro Marini, num diálogo com o conceito de semiperiferia, formulado por Immanuel Wallerstein.

Palavras-chave: Território; Subimperialismo brasileiro; Semiperiferia; Cooperação Antagônica; América Latina.

\section{THE ROLE OF BRAZIL IN LATIN AMERICA: A BRIEF REFLECTION OF THE BRAZILIAN SUB IMPERIALISM}

\begin{abstract}
In this article, we intend to raise some conceptual propositions that help us understand the Brazilian role in Latin America and, start a debate on the contemporary Brazilian foreign policy and its practical applications in geopolitics inserted into the world economy. For that, we aim to explain the concept of "multiterritorialidade", using the sub-imperialism thesis, by Ruy Mauro Marini, creating a dialogue with the concept of semi-periphery, formulated by Immanuel Wallerstein.
\end{abstract}

Key Words: Territory; Brazilian sub-imperialism; semiperiphery; antagonistic cooperation; Latin America

\section{Introdução}

Encaminha-se, desde os anos 60/70, um debate acerca da maneira como o Brasil vem se articulando nas decisões políticas e econômicas que se travam constantemente entre os governos latinoamericanos. Isso porque as novas estratégias do Estado brasileiro apoiam-se sob as bases da política externa e nas condições dadas por esta, ao mesmo tempo em que se renovam as relações do governo com a própria política doméstica.
Entender a posição que o Brasil se encontra nestas relações demanda uma reflexão sobre o contexto da política externa a partir de sua condição de país semiperiférico que, simplificadamente, delineia-se sob a tese do subimperialismo formulada por Ruy Mauro Marini. O presente artigo deseja investigar a validade desses elementos teóricos sem pretender, contudo, esgotar um debate que muito se deve explorar.

\footnotetext{
* Graduando em Geografia (Licenciatura Plena) pela Faculdade de Formação de Professores na Universidade do Estado do Rio de Janeiro. E-mail: plumuarte@hotmail.com

** Graduando em Geografia (Licenciatura Plena) pela Faculdade de Formação de Professores na Universidade do Estado do Rio de Janeiro. E-mail: guipercar@hotmail.com
} 


\section{Incursões preliminares: a multiterritorialidade como suporte teórico-analítico}

A reflexão que se pretende iniciar nas próximas linhas demanda, antes de tudo, uma discussão sobre o conceito de território e, em específico, sobre a multiterritorialidade. Ainda que não de forma exaustiva, interpretamos que a temática geopolítica que queremos debater consegue se desenvolver com 0 respaldo teórico daquilo que Haesbaert (1997, 2001a, 2002a, 2009, 2005) chamou de multiterritorialidade, pois a estrutura nos indica a sua relevância e nos aponta suas implicações na destruição e construção de novos territórios, concomitantemente. Deste modo, iniciaremos com a definição do termo que pretendemos estudar.

O termo multiterritorialidade surge na intenção em reafirmar que os movimentos de desterritorialização não se completam sem a sua contraparte, a reterritorialização. Haesbaert, resgatando a filosofia de Gilles Deleuze e Felix Guattari, emprega a multiterritorialidade para afirmar que a desterritorialização, sozinha, não consegue se desenvolver e, ademais, para destacar que a reterritorialização traz consigo múltiplos territórios, numa dinâmica tanto quanto complexa.

Destacamos, antes de tudo, que o território que será posto em análise é o território funcional, aquele cujo vetor de territorialização está contido nos processos de dominação. Funcional no sentido de significar fonte de recursos e riquezas ao capital que se nutre do lucro e da produção, através do controle físico de sua área. Esse controle, no entanto, não se limita aos recursos naturais assegurados pelas sociedades tradicionais, mas sim pelo controle dos fluxos que despontam pela mobilidade em redes e conexões, em resposta ao advento da "pós-modernidade". Haesbaert (2005) argumenta que essa necessidade de controle dos fluxos passa a dar atenção ao que o mesmo vai chamar de território-rede ou reticular (uma dimensão temporal-móvel do território [HAESBAERT, 2009]), aquele que consegue dar conta melhor dos reclamos do capital flexível, que se conecta concomitantemente com outros territórios, num processo de desreterritorialização, a partir de seus "módulos de conexão", as redes $^{1}$. Mas não apenas conexão de mercadorias, e sim de pessoas e, sobretudo, da informação.

A respeito disto, Milton Santos (2008) destaca que essa capacidade de mobilidade torna-se possível mediante os objetos técnicos, que são aqueles criados para a facilitação da fluidez virtual. Essa, por sua vez, instaura uma nova dinâmica no território, construindo-o sob novas formas, desenhadas e configuradas pelas verticalidades do território, expressão análoga ao termo rede; e, também, pelas horizontalidades, aí num sentido mais voltado para o controle de áreas pelo Estado, através dos domínios da contiguidade.

Jean Gottmann também se atém a este debate, "quando reconhece a existência de centros e periferias, de desigualdades e de centralidades, ratificando a fluidez moderna, facilitada pelas redes de circulação e comunicação, como produto de mudanças econômicas e políticas" (SAQUET, 2010:69). $\mathrm{Na}$ década de 1980 o autor identifica um aumento no movimento e reorganização do espaço no sistema mundial, ou mesmo, reconhece a compressão tempo-espaço de Harvey e afirma que o espaço, hoje, se converte a uma dinâmica mais flexível e aberta, adaptando-se a um novo território, agora reticular. 
Com isso, temos a passagem do recorte territorial delimitado por fronteiras, o território-zona ou zonal para o territóriorede, não caindo no erro da dicotomia e entendendo, pois, que os "dois" territórios se sobrepõem e/ou se complementam (HAESBAERT, 2009), ocupando-se de escalas múltiplas e nem sempre esclarecidas. O território do Estado-nação, fechado, se surpreende com a "pós-modernidade" e se articula com outros territórios, admitindo sua transnacionalização (SANTOS, 2009).

Ainda sobre 0 território-rede, poderíamos ressaltar que os múltiplos territórios em conexão engajam-se em redes a partir de determinados graus, "daquilo que poderíamos denominar como sendo a conectividade e/ou vulnerabilidade informacional (ou virtual) dos territórios" (HAESBAERT, 2004:345 apud HAESBAERT, 2005:6788). Daí Milton Santos destacar o papel do meio técnico-científico informacional que contribui para o avanço da informação que, para Harvey, permite permutas na apreensão do homem em sua espacialidade, a partir da compressão do tempo-espaço. No trecho a seguir, Harvey (2011) deixa claro que esta expressão indica os

(...) processos que revolucionam as qualidades objetivas do espaço e do tempo a ponto de nos forçarem a alterar, às vezes radicalmente, o modo como representamos o mundo para nós mesmos. Uso a palavra "compressão" por haver fortes indícios de que a história do capitalismo tem se caracterizado pela aceleração do ritmo da vida, ao mesmo tempo em que venceu barreiras espaciais em tal grau que por vezes o mundo parece encolher numa "aldeia global" de telecomunicações. (p. 219)

Por fim, Haesbaert (2005) propõe pensar os agentes que se desdobram para a promoção da multiterritorialização, sejam as instituições, as empresas e/ou o próprio
Estado que, para alguns autores, são vetores que contribuem para a desterritorialização. É o que propõe, por exemplo, Marina Faccioli. Ainda que reconheça a rede como vetor da desterritorialização, a geógrafa italiana afirma que os sistemas produtivo-territoriais, cunhadas pelas empresas a partir do controle, gestão e relações de poder numa dada descontinuidade territorial, constroem o território através dos fluxos e das deslocalizações.

Faccioli chega a falar de uma trama territorial para evidenciar 0 papel das empresas, "com a efetivação de uma crescente imaterialidade de aspectos do ciclo produtivo (informações e conhecimento)" (SAQUET, 2010:101). Esta trama se dá sob duas formas: em primeiro lugar, a partir das redes de informação que contribuem para a flexibilização da produção e, em segundo lugar, mediante a interação entre sistemas territoriais distintos, tornando o território mais imaterial e menos zonal, areal.

Nesse sentido, outros autores da literatura italiana seguem as mesmas tendências e travam um diálogo direto entre o território e a atuação das empresas. Exemplificando, temos: Morelli (1993), que afirma ser o território uma área de atuação empresarial, onde se travam relações empresariais a partir de uma lógica hierárquica, reticular, em meio à tecnologia e inovação; Cerreti (1993), que também vê o território como o espaço das empresas que comandam sua organização a partir dos sistemas de empresas (SAQUET, 2010).

Há, contudo, autores que vão analisar a lógica da restruturação territorial e afirmar que o território não perde sua materialidade diante das conexões realizadas pela técnica da informação. Enzo Rullani (1997), por exemplo, ratifica as afirmativas feitas por Haesbaert, quando expõe que "no movimento de reprodução do valor, as ações econômicas 
têm, necessariamente, uma projeção extralocal, uma conexão no mercado. Entende que o território, mesmo com a globalização da economia, não é anulado" (SAQUET, 2010:105). Para o autor, o território não é apenas enraizamento, mas também identidade e conexão.

Gostaríamos de esclarecer dois pontos: i- os agentes que controlam os múltiplos territórios, em rede, estabelecem uma regionalização ao mesmo tempo em que não deturpam a materialidade do território; ii- a materialidade do território existe, em concomitância com o território-rede, e nos ajuda a entender as alianças e cooperações que o Brasil vem travando com os governos latino-americanos como liderança regional, objetivando o controle dessas áreas sob a trama territorial que se constrói a partir dos interesses político-econômicos.

Feito as devidas considerações, passemos para o segundo momento deste artigo, onde faremos uma breve análise sobre a tese do subimperialismo brasileiro colocando o Brasil na posição de semiperiferia no sistema mundial.

\section{- subimperialismo brasileiro e o conceito de semiperiferia: um diálogo necessário}

Contudo, a semiperiferia não é um artifício de pontos de corte estatísticos, nem uma categoria residual. A semiperiferia é um elemento estrutural necessário em uma economia-mundo. Estas áreas têm um papel paralelo ao representado, mutatis mutandis, pelos grupos comerciantes intermédios em um império. São pontos coletores vitais, com frequência politicamente impopulares. Estas áreas intermédias (como os grupos intermédios em um império) desviam parcialmente as pressões políticas que os grupos localizados primariamente nas áreas periféricas poderiam em outro caso dirigir contra os Estados do centro e os grupos que operam no interior e através dos seus aparelhos de Estado. Por outro lado, os interesses localizados basicamente na semiperiferia acham-se no exterior da arena política dos Estados do centro, e é-lhes difícil prosseguir os seus fins através de coligações políticas que poderiam estar abertas para eles se estivessem na mesma arena política. (WALLERSTEIN, 1990:339 apud SANTOS, 2006:51)

Pouco se tem visto autores que conseguem intensificar 0 debate sobre 0 conceito de semiperiferia formulado por Immanuel Wallerstein (1974), surgido em The Modern World-System. Talvez isso tenha ligação com suas formulações gerais, que não foram aprofundadas e estruturadas suficientemente. Sousa Santos (1985) chega a dizer que semiperiferia "não tem passado de um conceito descritivo, vago e negativo" (p. 2).

Este conceito discute os novos atores que se projetam no sistema-mundo em meio aos polares, ou seja, aos países centrais e periféricos. De modo geral, o Estado semiperiférico sustenta sua economia na "produção de produtos manufaturados para o mercado interno (...)" e são "também exportadores de produtos primários, desempenhando 0 papel de parceiros periféricos face aos países centrais e de parceiros centrais a alguns países periféricos" (WALLERSTEIN, 1972: 247 apud FORTUNA, 1986: 16).

O conceito de semiperiferia, acompanhado com a teoria do sistemamundo, se vale pela análise das estruturas tripartites da economia-mundo ou trimodal em detrimento da estrutura bimodal. O que na prática significa dizer que centro e periferia deixam 0 protagonismo com a entrada dos debates sobre o surgimento conceitual de semiperiferia. Fortuna (1986) argumenta que "a sua base histórica de análise permite-Ihe conceber a semiperiferia não como uma condição transitória e 
residual, mas estável, permanente e relacional" (p. 14).

Não como uma condição transitória porque voltaríamos a um debate já antigo sobre a teoria da modernização, que a pensa como uma condição transitória, passageira, apenas como um deslocamento para o desenvolvimento. E não residual, na medida em que passaríamos a olhar um Estado semiperiférico não como ele é, mas como periferia ou centro, pois a teoria da dependência discute, de modo geral, a crescente polarização do mundo capitalista e descarta outras disposições geopolíticas.

O Estado semiperiférico consegue alçar estratégias próprias para sua permanência e estabilidade, através de suas relações com os polos já estabelecidos no sistema mundial, obedecendo aos limites políticos e interesses geopolíticos de cada um como visto anteriormente. Essas estratégias são alçadas sob os aglomerados de demandas políticas (conflitos internos e externos, pressões interestatais) que não fazem da semiperiferia um conceito cabível para todos os Estados de novas tendências.

$\mathrm{Na}$ verdade, todos os interesses internos e externos são vetores que levam esses Estados a níveis distintos de semiperiferia. É o que Fortunado (1986) chama de despromoção ou periferialização e centração, que seria na verdade a centralização dessas semiperiferias no sistema-mundo.

A despromoção pode ser explicada pela dinâmica intensa que é interpretada quando falamos do Estado central e de sua maturidade econômica que, para o autor, é o agente que pode levá-lo ao processo de despromoção técnica e estrutural, a partir da recombinação na estrutura social e na desreterritorialização dos fluxos de capitais, das empresas e da produção.
Preciado (2008) traz esse debate

teórico para a América Latina e chama atenção para as semiperiferias diversas que são postas em análise, subdividias em: i) semiperiferia ativa ou potência global autônoma, caso do Brasil que critica o funcionamento dos poderes centrais e preza por sua autonomia na região; ii) semiperiferia emergente, caso da Venezuela, que se mostra como um Estado "alternativo", portanto, anti-hegemônico; iii) semiperiferia subordinada, caso do México que, na relação Norte-Sul num eixo econômico-comercial, adere aos Tratados de Livre Comércio da América do Norte.

O debate sobre o Estado semiperiférico deve sempre transcorrer por sua capacidade de manobra política e institucional dentro do sistema-mundo, pois "esta centralidade do Estado é um traço essencial da relação da semiperiferia como o mercado, o capital e o trabalho, como é também do desempenho dos diferentes estados nacionais a nível do sistema interestados" (FORTUNADO, 1986: 20).

Martins (2002), ao resgatar as ideias de Arrighi (1997), se dispõe a pensar no surgimento da semiperiferia como a superação do caos sistêmico que se estabeleceu através da reprodução do padrão de riqueza criado pelas "oligarquias" e "por un patrón mundial de riqueza democrática" (p. 11). Esta superação tornou-se possível mediante as lutas travadas pelas semiperiferias, embora algumas ainda hoje não sejam anti-sistêmicas. Esta clivagem no caos sistêmico pode ser provocada por alguns aspectos específicos, como:

1. Un giro en la política de los países semiperiféricos y periféricos en dirección centro-izquierda y a la izquierda. Acelerándolo está el agravamento de la superexplotación del trabajo que afectará negativamente los patrones de vida de esas sociedades. Este giro debe 
significar no ya políticas paliativas que combatan la pobreza, sino más bien una política activa de combate de sus causas determinantes; y

2. La articulación de las políticas de lucha contra la explotación y la exclusión por parte de los movimientos nacionales y regionales, de la periferia y semiperiferia. Esa articulación es fundamental para minimizar las represálias que parten de los centros y, aceleradas por la capacitación absorbida a partir de la difusión, crean una importante fuerza económica, política, social y cultural en el sistema mundial. (p. 12)

Interpretamos que a semiperiferia antisistêmica apontada por Martins expressa, pelo menos parcialmente, a postura subimperialista do Brasil diante dos governos da América Latina. Isso porque enquanto o governo brasileiro emerge como um novo ator no sistema-mundo (aquele que adequa seus interesses às intenções vindas das políticas externa e hegemônicas) se admite como liderança no subsistema regional sulamericano (LUCE, 2007). Tudo isso atrelado a uma nova divisão internacional do trabalho que se forma.

Em 1967, o conceito de subimperialismo, aliado à concepção da nova divisão internacional do trabalho em formação, já apontava para o surgimento dos novos países Industriais (os NICs), entre os quais vieram a destacar-se, posteriormente os tigres asiáticos. Há pouco, James $\mathrm{O}^{\prime}$ Connor me escrevia, em uma carta, com certo humor, que o conceito de semiperiferia de Immanuel Wallerstein correspondia de fato àquilo 'que nós chamávamos sub-imperialismo'. (p. 22) ${ }^{2}$

\section{Uma breve análise sobre a tese do subimperialismo brasileiro}

A visão de Ruy Mauro Marini permite, ao mesmo tempo, entender o esgotamento da capacidade do capitalismo latino-americano de retomar o desenvolvimento de forma sustentada, com distribuição de renda e expansão minimamente orgânica das forças produtivas. As burguesias de cada país se desnacionalizam cada vez mais, atrelando seus interesses e

destinos aos do $\begin{array}{r}\text { mercado } \\ \text { modelos }\end{array}$
internacional,
exportadores. Seus ciclos expansivos,
além de curtos, aprofundam o caráter
desigual do desenvolvimento e
deformam cada vez mais sua
estrutura econômica, rom
consequências de profundos
desequilíbrios no plano social. O
desenvolvimento econômico possível
na América Latina se daria somente
com om aprofundamento da
dependência e da desigualdade
social. (p. 32) ${ }^{3}$

No período do pós-guerra, abriu-se uma discussão inesgotável sobre o desempenho do Estado brasileiro na economia-mundo (Braudel, 1976) ${ }^{4}$, que passava a propor novas bases estratégicas (econômica e política) para o desenvolvimento de sua política externa. Essas estratégias eram acomodadas de acordo com o papel do governo frente aos demais Estados do continente americano. Foi neste cenário que, nos anos 60 e 70, o cientista social brasileiro Ruy Mauro Marini formulou a tese do subimperialismo brasileiro ${ }^{5}$. A respeito deste período, Emir Sader expõe que "a ditadura militar, ao contrário do que alguns previram, não significou um retrocesso na expansão econômica, mas o seu redirecionamento, voltando-se mais para o mercado externo e para as altas esferas do consumo" (p. 29). ${ }^{6}$

O Brasil, na análise de Marini, se comportava como os países imperialistas, pois, ainda que subordinado e dependente dos mesmos, inaugurou uma nova etapa "da exportação de capital e manufaturas, bem como do controle de matérias-primas e fontes de energia no exterior" (LUCE, 2007: 12). Poderíamos afirmar, deste modo, que o Brasil entrou na esfera de desenvolvimento econômico, ainda que sob as rédeas dos países imperialistas, em concomitância com o seu rearranjo nas decisões políticas internacionais. Portanto, "enquanto potência média, o Brasil exerceria no subsistema 
regional de poder sul-americano, um papel expansionista análogo ao dos Estados imperialistas, porém sob laços de dependência perante as economias dominantes" (LUCE, 2007: 12).

A tese, por muito influenciada pelo marxismo, destacou que o Brasil continuava sendo dependente das grandes potências, mesmo sendo ele um Estado de destaque na região sul-americana. Esse destaque pode ser caracterizado segundo o seu papel de mediador ou intermediário diante da reorganização das relações internacionais "que configura os blocos de poder central em direção à periferia" (PRECIADO, 2008: 1). Esta relação de dependência é um dos pontos que integra a tese de Marini à ideia de potência autônoma. E a condena quando argumenta que um país como o Brasil, ainda que sob as formas de transformação políticoeconômica em escalas local, regional e global, não possui condições apropriadas para configurar-se como uma potência autônoma, pois a dependência frente aos países hegemônicos ainda persiste.

É importante ressaltar que a dependência brasileira surge com as suas relações de produção com os países centrais, mas surge no intuito em provocar ainda mais a reprodução de sua dependência. Peter Taylor, a propósito, chama atenção para o termo semiperiferia ativa7, quando traça este paralelo entre produção e dependência (Preciado, 2008). Para Taylor, dizer que um país funciona como uma semiperiferia é alegar que este combina os processos de centro e de periferia. Isto é, passa a explorar os países ditos periféricos enquanto é explorado pelos países centrais ${ }^{8}$.

Estes processos combinados que Taylor propõe é o que Marini vai chamar de forças vindas dos países dominantes ou metropolitanos (centrais) e dos países subdesenvolvidos (periféricos).
Todo este emaranhado de relações entre o Brasil, a periferia e o centro provocou uma série de mudanças na configuração da sua economia interna, forçando a burguesia nacional a se utilizar de novas estratégias. Estas transformações fez do país, que atingira uma composição orgânica média nacional do capital, um aliado do capital dos Estados Unidos, país que faz parte do grupo central da economia mundial. LUCE (2007) nos alerta que:

Entre os efeitos provocados por essa situação nos países dependentes, encontram-se a inibição da demanda efetiva interna e a redução do excedente econômico investível. Ambos tornaram-se fatores a obstacularizar a continuidade do processo de industrialização nos marcos capitalistas, ao reduzir o mercado consumidor e a capacidade de importar maquinaria. As contradições daí advindas geraram um impasse cujo desfecho acabou por provocar o fracasso do projeto nacional-desenvolvimentista e a consequente integração do Brasil ao imperialismo como solução encontrada pela burguesia brasileira para assegurar seu poder, mesmo sob a condição de sócia menor do capital do centro dominante. O desenrolar desse processo trouxe dois desdobramentos significativos. Enquanto o problema da tecnologia conduziu à integração ao capital estrangeiro como meio de levar adiante a industrialização, a solução encontrada para o exíguo mercado interno foi o recurso ao comércio exterior como fator de realização de capital. (p. 13)

Para esta aliança contraditória entre o Brasil e os Estados Unidos, no binômio centro-semiperiferia ou, ainda, centropotência regional, Marini reservou um termo: cooperação antagônica. Termo que, aliás, fora criado pela marxista alemão August Thalheimer ${ }^{9}$. A cooperação antagônica identifica nesta dinâmica um jogo de papéis que se intercruzam. De um lado, temos o Brasil promovendo sua influência em nome de sua expansão pela região latino- 
americana, a partir de sua posição intermediária na divisão internacional do trabalho. De outro, temos os Estados Unidos que estão, antes de tudo, reafirmando três fatores político-estratégicos primordiais: sua influência na América Latina, seu papel enquanto poder central na região e a manutenção da dependência do Brasil.

A relativa autonomia brasileira neste jogo sustenta a afirmação de Preciado (2008) quando argumenta que "o Brasil demarca claramente as características de um poder regional, e procura, com crescente sucesso, seu posicionamento como um superpoder" (p. 260). Este é o ponto fundamental que o diferencia do México (outro importante "Estado âncora" regional) que, por sua vez, não busca demasiadamente sua autonomia, e sim intensifica seu papel de subordinação ao centro estadunidense.

Bugiato e Assumpcao

(2010) sustentam a ideia de que o Brasil se mostra como uma potência "autônoma"10 porque atua na política externa sem "(...) ter elegido um parceiro e aliado exclusivo" (p. 7). E isso se torna possível mediante a formação de três grupos de governos que se relacionam com os Estados Unidos e com as políticas de avanços democráticos e nacionais.

O primeiro grupo, formado por Chile, Peru, Colômbia, México e Guatemala estão diretamente ligados aos comandos dos Estados Unidos, a partir da assinatura dos Tratados de Livre Comércio e de cooperação militar. O segundo grupo é formado pelos países da ALBA (Alternativa Bolivariana para as Américas) e por aqueles que possuem um discurso que pretende diferenciar-se dos ditames imperialistas, como Venezuela, Equador e Bolívia. O terceiro grupo, por fim, é onde o Brasil se insere, juntamente com Argentina, Uruguai e Paraguai. Este último, denominado pelos autores como grupo de centro $^{11}$, articula-se ora com os Estados
Unidos, ora com os países centrais e com os países ditos "alternativos".

Essa articulação, no entanto, não se projeta sem o surgimento de conflitos e outras opções políticas como estratégia. Há de se destacar, por exemplo, a tensa relação do Brasil com os países alternativos (Equador, Bolívia e Venezuela), a partir da atuação das empresas nacionais em seus territórios ou, ainda, com a própria Argentina pelas mesmas motivações. Também poderíamos apontar os conflitos com os Estados Unidos, em resposta à política econômica do algodão na OMC. E, como opção estratégica do governo diante de conflitos interestatais, cabe ressaltar a liderança do governo brasileiro na reunião da UNASUR durante a crise interna da Bolívia e a mediação no conflito entre Colômbia e Equador (Bugiato e Assumpcao, 2010).

Isso se apresenta como resultado da tentativa do governo brasileiro em se desdobrar para tomar o cuidado em não despertar tensões políticas com os Estados Unidos (quando, por exemplo, falamos da ocupação militar brasileira no Haiti) e, sobretudo, com os países da América do Sul, pois o propósito do Brasil é, indubitavelmente, a integração regional, "pela sua função de 'locomotiva' econômica na dinamização da região por meio da integração comercial e da integração física energética, logística e de infra-estrutura" (SENHORAS; VITTE, 2007: 6).

Observando a atuação brasileira no sistema internacional há uma variação combinada de táticas: o Brasil alterna momentos de adesão com momentos autonomistas e em ambas situações busca capitalizar liderança e protagonismo dentro dos processos de integração e atuação multilateral. (MACHADO, 2004: 2 apud SENHORAS; VITTE, 2007: 4)

Senhoras e Vitte (2007) destacam que a política externa do Brasil se estabelece sob 
dois fatores: i) a partir de uma integração branda, sem ousar criar um mal-estar diplomático entre os governos latinoamericanos, a partir de cooperações e negociações mediadas por um diálogo satisfatório às partes; ii) o segundo fator é o complemento do primeiro, na medida em que busca não despertar conflitos como os do passado. Nesse sentido, o Brasil se utiliza de discursos de integração da América Latina sem se mostrar como líder desta.

\section{A cooperação antagônica como categoria de análise do subimperialismo brasileiro}

Não pretendemos, aqui, perscrutar a história da cooperação antagônica, suas formulações, suas condições de existência e toda a sua estrutura categorial. Interessa-nos compreender a cooperação antagônica de modo que possamos usá-la para o entendimento da atuação do Brasil na América Latina.

A cooperação antagônica explica, logo de saída, a política de integração do Brasil na América Latina e sua incursão expansionista pelo continente. Os conflitos e alianças com os Estados Unidos, juntos, são detectados pelas formulações da cooperação antagônica. Quando se fala em projeto expansionista do Estado brasileiro fala-se também das suas amarras e dependências com os Estados Unidos, pois o Brasil funciona como "Estado âncora" (PRECIADO, 2008) dos interesses estadunidenses, bem como o México (mas não sob os mesmos aspectos, como já visto).

$\mathrm{Na}$ prática, isso significa dizer que o Brasil é o interlocutor, o intermediário, o porta-voz dos Estados Unidos na América do Sul, papel inclusive almejado pelo México que, por sua vez, "caiu na contradição de conformar-se em ser um país latinoamericano que escolheu um projeto estratégico de integração profunda em direção ao Norte" (PRECIADO, 2008: p. 261).
Deste modo, a cooperação se torna antagônica quando o mesmo Brasil interlocutor estadunidense se utiliza deste artifício para projetar-se como uma potência regional. E mais, quando aliado aos EUA, entra num embate com seus interesses e instaura, muitas vezes, um mal-estar diplomático.

O autor Michael Morris, em sua tentativa em resgatar a tese do subimperialismo de Marini, enfatiza a lógica do termo potência média. Este termo surge na análise das práticas desenvolvidas no chamado subsistema regional. Morris (1981) chega a construir um quadro tentando demonstrar a hegemonia regional das potências médias.

Para o Brasil, o autor reservou o lugar de hegemonia regional, dentro do sistema regional (América Latina) e, em escala reduzida, do sistema sub-regional (América do Sul). Ser considerado, o Brasil, como hegemonia regional significa competir vantajosamente com o poder rival regional (Argentina) e com os outros Estados Estados-tampão (Bolívia, Paraguai e Uruguai), os Estados regionais (Chile, Colômbia, Equador, Guiana, Peru, Suriname e Venezuela) e com a potência dominante, Estados Unidos.

Esta ambivalência (Becker e Egler, 2010) instaurada dá margem, portanto, aos debates contundentes sobre 0 arranjo político-econômico do Brasil como hegemonia regional dentro da economia-mundo ou, como quer Peter Taylor, do sistema-mundo. Sua possibilidade se dá sob três escalas de poder, segundo Becker e Egler (2010): i) o primeiro poder diz respeito ao caminho estratégico que o Brasil deve desempenhar numa região em que já se tem estabelecida uma ordem de poder vinda de um país hegemônico - trata-se, aqui, do domínio dos Estados Unidos na América Latina; ii) o 
segundo poder vem do poder rival regional, no caso da Argentina, que tenta incessantemente concorrer com o Estado brasileiro nas decisões em blocos supranacionais e em alianças travadas no Cone Sul; iii) e o terceiro poder "expressa o controle político do território e da sociedade que no Brasil assumiu a forma de um projeto nacional autoritário" (p. 18) ${ }^{12}$.

A Argentina rivaliza com o Brasil há anos, inclusive como uma subpotência. Entretanto, nas afirmativas de Marini, o Estado argentino jamais conseguiu atingir o status brasileiro de subimperialista, pois é incapaz de controlar suas decisões na América do Sul (subsistema regional de poder) e hegemonizá-las, além de funcionar como intermediário da potência dominante. Marini chama esta capacidade brasileira (mas não privilégio) de interdependência imperialista.

\section{Cooperação interdependência assimétrica entre Brasil e EUA}

A cooperação antagônica que se desenha entre os Estados parte de dois fatores fundamentais: liberalização e estabilização (LUCE, 2007). A liberalização econômica brasileira pretende resguardar as forças do Brasil diante do superpoder estadunidense. Mesmo com todos os acordos mútuos e decisões "cômodas" aos dois, o Brasil entende que é necessário defender a burguesia nacional e criar uma alternativa à ALCA, "a partir da convergência entre MERCOSUL e CAN e de outras iniciativas como a IIRSA" (LUCE, 2007: 53).

A criação do MERCOSUL (1991), com a assinatura do Tratado de Assunção, avançou nas questões de integração econômico-comercial Sul-Sul e promoveu o Brasil ao cargo de liderança do bloco supranacional. Em relação a este fato, cabe destacar que:

O MERCOSUL seria uma nova
tentativa que buscaria não repetir os
erros anteriores. Até finais da década
de 1990 não transparecia em seu
bojo o intercâmbio desigual, já que o
Brasil, devido à apreciação do real,
obteve déficits comerciais, que
favorecia as contas externas dos
demais sócios. Com a mudança do
fator cambial em 1999, no entanto,
os saldos comerciais passaram a ser
revertidos, de tal maneira que, hoje,
países queixam-se das assimetrias no
bloco e questionam sobre quais os
ganhos objetivos que podem ser
obtidos participando dele, numa
crítica que teria feito retornar a
questão do subimperialismo.
(GUDYNAS, 2004 apud LUCE, 2007:
57)

Não repetir os erros anteriores significa não resgatar o que fora feito no projeto da ALALC/Mercado Comum Latinoamericano (1960). Nesse momento, o intercâmbio desigual foi instaurado, beneficiando as "empresas brasileiras e as corporações estrangeiras, sobretudo estadunidenses, em operação na região" (LUCE, 2007: 57). Isso gerou incômodos aos países da Associação Latino-americana de Livre Comércio (ALALC) que se sentiram prejudicados com tais práticas econômicas e comerciais. Em suma, a liberalização é a estratégia brasileira de relacionar-se com os Estados Unidos, mas tomando as devidas precauções, evitando acordos amplos que façam do projeto de integração sulamericana um fracasso.

Já a estabilização, diz respeito às relações traçados pelo Brasil com os Estados anti-hegemônicos (Bolívia, Equador e Venezuela). A Venezuela, por exemplo, em seu papel de Estado regional (assim considerado por ter uma capacidade de liderança regional no setor energético), possui um poder ideológico de luta contra os preceitos anti-imperialistas. $E$ isso, na 
prática, "questiona os fundamentos básicos de exploração das periferias no sistemamundo, assim como a dependência dos centros mundiais" (PRECIADO, 2008: 263).

Toda esta capacidade ideológica venezuelana é abrandada pelo jogo diplomático do governo brasileiro, que tenta a todo o momento impor as suas demandas e necessidades em consonância com os interesses maiores dos Estados Unidos. No entanto, quando esses mesmos interesses se territorializam nas áreas de influência brasileira, surge então um agravo entre os dois Estados. Isso pode ser verificado nos planos estadunidenses de militarização na América Latina.

Por outro lado, quando este eixo político-militar é circunscrito fora dessas áreas de influência brasileira, o Brasil abona suas preocupações e trava, como em alguns casos, parcerias com os Estados Unidos bem como acontece no Haiti, uma área de influência direta estadunidense (tudo em nome do interesse do Brasil em conseguir uma vaga no Conselho de Segurança da ONU).

Estes mesmos fatores (liberalização e estabilização/militarização) também são aplicados pelos Estados Unidos na intenção em propalar a sua geopolítica. Na América Latina, a estabilização/militarização é realizada através das medidas preventivas de instalação de bases militares na região.

Na América do Sul, a presença militar na Colômbia afigura-se como o elo principal dessa corrente, que abrange também outras posições, como a base de Manta, no Equador, e as de Aruba e Curaçao, nas Antilhas holandesas. (LUCE, 2007: 37)

Preciado (2008) chama atenção para este caráter de militarização dos Estados Unidos, quando ressalta que a condução do eixo político-militar ganha força na região com a delimitação da Área de
Responsabilidade do Comando Norte (AOR) que, segundo o autor, "projeta a mais contundente extensão do perímetro de segurança regional norte-americano" ( $p$. 256). ${ }^{13}$

As áreas de influências também são legitimadas com determinados planos interestatais, como o Plano Colômbia, o mais importante na América Latina, e sua extensão, a Iniciativa Regional Andina (Preciado, 2008).

E o Brasil, em torno deste contexto, se desloca como "país-costura" dos Estados Unidos. Isso porque o Estado brasileiro cumpre com as demandas estadunidenses em troca de algumas concessões (LUCE, 2007). Este termo, aliás, vem do Relatório da Marinha dos EUA, intitulado Novo Mapa do Pentágono, criado por Thomas Barnett para acentuar as três zonas de influência estadunidense no globo: a primeira refere-se ao centro, composto pelos países desenvolvidos; a segunda à zona de "brecha", que demanda dos EUA mais controle e vigilância, por ser considerada de alto risco; a terceira zona refere-se aos países "costura ou elo", que fornecem subsídios para o disciplinamento dos países da segunda zona (CECEÑA, 2005a apud LUCE, 2007).

\section{Considerações Finais}

As análises sobre a atuação do Estado brasileiro têm mostrado que as mudanças em sua política interna são acompanhadas pelas transformações verificadas na região latinoamericana, sobretudo na América do Sul. O que confere validade a esta afirmação é o teor de investigação que se tem feito sobre o Brasil enquanto potência, ainda que regional e subordinado ao capital orgânico dos imperialismos estadunidense e europeu. 
Quando os estudos afirmam que o Brasil se reconhece como potência regional, significa dizer que a sua estrutura, hoje, não pode ser a de um país central, nem mesmo a de um país periférico. A sua nova estrutura já não nos permite falar da estrutura bimodal. A emergência por uma alternativa se instaura e nos faz compreender que a complexidade é posta, exigindo um novo arranjo estrutural. Alguns autores procuram, a partir disso, tratar o Brasil como um país semiperiférico, aquele que se renova na divisão internacional do trabalho e apreende novas demandas em sua agenda política. Outros, no entanto, preferem chamá-lo de potência regional internacional (MONIZ BANDEIRA, 2008), e dar destaque aos elementos ditos fundamentais para que um Estado consiga chegar ao nível de potência: extensão territorial, poder econômico e poder militar.

Como já abordado, o Brasil se projeta no subsistema regional sul-americano num plano expansionista em relativa autonomia, recombinando estratégias para se estabilizar na etapa de monopólios e do capital financeiro. Todos esses elementos compõem a tese do subimperialismo brasileiro. Deste modo, o artigo se propôs a traçar uma interface entre a tese formulada por Marini e o conceito de semiperiferia, cunhada por Immanuel Wallerstein, para dar conta desta nossa reflexão.

\section{NOTAS}

1 Os múltiplos territórios que se conectam em rede inauguram a desterritorialização, como querem alguns autores. Manuel Castells, por exemplo, chega a falar da desterritorialização a partir do advento da sociedade em rede ou sociedade-rede, que deturpa as divisões territoriais bem demarcadas dos Estados-nação (HAESBAERT, R.; LIMONAD, E., 1999). Paul Virilio é outro autor que defende a ideia da desterritorialização, quando em sua obra, Guerra Pura (1982), ataca essas novas tecnologias informacionais e as chama de "tecnologias desterritorializadoras" (HAESBAERT, 2009).

2 DOS SANTOS, Theotonio. Ruy Mauro Marini: um pensador latino-americano. In: A América Latina e os desafios da globalização. Rio de Janeiro; São Paulo: PUC-Rio; Boitempo Editorial, 2009, p. 2126.

3 Idem.

4 O sistema-mundo é entendido por Wallerstein como um conjunto de relações que se estabelecem no espaço. Relações múltiplas e complexas que dão base ao que chamamos de economia-mundo. A economia-mundo é, na definição do próprio Braudel (1979), "(...) uma incrustação, uma justaposição de zonas ligadas conjuntamente, mas em níveis diferentes" (III, 35 apud LIMA, 2007: 2).

5 "La génesis del concepto de subimperialismo deriva del análisis de Marini sobre el tormentoso período de la historia brasileña que fueron los quince años acaecidos entre 1950 e 1964, cuando la agudización de la lucha de clases y la crisis del proceso de industrialización generaron tensiones disruptivas en el seno del capitalismo brasileño, desembocando al acontecimiento político-militar de 64 e el comienzo de una nueva fase, el subimperialismo" (LUCE, 2008: 2).

6 SADER, E. S. Ruy Mauro, intelectual revolucionário. In: A América Latina e os desafios da globalização. Rio de Janeiro; São Paulo: PUCRio; Boitempo Editorial, 2009, p. 27-35.

7 "A geografia política que Taylor desenvolve retoma, como base de identificação espacial, as estruturas tripartites da economia-mundo centros, periferias e semiperiferias - que são entendidas por Wallerstein como processos de exploração da economia-mundo, e também implicam uma representação espacial do mundo ligada às mudanças de ritmo dos ciclos de auge e crises dos que estão submetidos à economia capitalista" (PRECIADO, 2008: 254).

8 "Os processos de centro consistem em relações que combinam salários relativamente altos, tecnologia moderna e um tipo de produção 
diversificada. Os processos da periferia constituem uma combinação de baixos salários, tecnologia mais rudimentar, resultando num tipo de produção simples" (PRECIADO, 2008: 255).

9 "Originalmente criado pelo marxista alemão August Thalheimer, em sua obra Grundlinier un Grundbegriffe der Weltpolitik nach dem zweitein Weltkrieg, o conceito de cooperação antagônica foi historicamente formulado ao término da Segunda Guerra Mundial.

10 "Autônoma no sentido de criar uma esfera de influência regional própria, respondendo pelos interesses das frações nacionalitárias do capital". (LUCE, 2007: 13)

11 Neste contexto, o grupo de centro referido diz respeito aos países que conversam diplomaticamente com os países hegemônicos ou centrais ao mesmo tempo em que se articulam entre si e com os países anti-hegemônicos ou ditos "alternativos".

$12 \mathrm{O}$ projeto nacional autoritário expressou a nova política externa brasileira iniciada na década de 1970, sob os parâmetros neonacionalistas. Nesse momento, o Estado brasileiro entendia que um projeto nacional o ajudaria em sua emancipação na geopolítica internacional, em meio às crises internacional e nacional e ao relativo enfraquecimento dos Estados Unidos. A respeito disso, ver Becker e Egler (2010), capítulo IV.

${ }^{13}$ A Área de Responsabilidade do Comando Norte (AOR) "(...) compreende desde o Alasca até a fronteira sul mexicana, incluindo parte do Caribe, e 500 milhas náuticas tanto do Pacífico como do Atlântico" (PRECIADO, 2008: 256). 


\section{REFERÊNCIAS BIBLIOGRÁFICAS}

BUGIATO, Caio; ASSUMPCAO, T. B. Governo Lula: autonomia externa ou subimperialismo?, in: Simpósio Lutas Sociais na América Latina, 2010, Londrina. Anais do IV Simpósio Lutas Sociais na América Latina, 2010. p. 137-146.

DOS SANTOS, Theotonio (Org.); MARTINS, Carlos Eduardo (Org.); VALENCIA, A. Sotelo (Org.); SADER, Emir (Org.). 2009. A América Latina e os desafios da globalização: ensaios dedicados a Ruy Mauro Marini. Rio de Janeiro; São Paulo: PUC-Rio; Boitempo.

FORTUNA, Carlos. 1986. Desenvolvimento e sociologia histórica: acerca da teoria do sistema mundial capitalista e da semiperiferia. Lisboa, CIES/ISCTE.

HAESBAERT, R. ; LIMONAD, E. 1999 . O território em tempos de globalização. Geo UERJ, Rio de Janeiro, v. 5, p. 7-19.

2002. Territórios Alternativos. São Paulo: Contexto. v. 1. $186 \mathrm{p}$.

2005. Da

Desterritorialização à Multiterritorialidade. In: X Encontro de Geógrafos da América Latina, 2005, São Paulo. Anais do X Encontro de Geógrafos da América Latina. p. 6774-6792.

$$
\text { 2009. O mito da }
$$

desterritorialização: do "fim dos territórios" à multiterritorialidade (4a ed.). 4. ed. Rio de Janeiro: Bertrand Brasil.

HARVEY, David. 2011. Condição PósModerna (Uma pesquisa sobre as origens da mudança cultural). São Paulo: Edições Loyola.
LIMA, P.G.C. 2007. Posicionamento no sistema mundial e semiperiferia, in: Periódicos UFSC, v. 10, n. 2. Santa Catarina: UFSC.

LUCE, Mathias Seibel. 2007. O subimperialismo brasileiro revisitado: a política de integração regional do governo Lula (2003-2007). Dissertação (mestrado em Relações Internacionais). Porto Alegre: UFRGS.

2008. La expansión del subimperialismo brasileño. Patria Grande, v. n.9, p. 48-67.

MARTINS, Carlos Eduardo. 2002. Los desafíos del sistema mundial para el siglo XXI: perspectivas para América Latina. Economía Crítica Desarrollo, v. 1, n. 1, p. 17-34.

MONIZ BANDEIRA, Luiz Alberto. 2008. O Brasil como potência regional e a importância estratégica da América do Sul na sua política exterior. Temas \& Matizes (Impresso), v. 8, p. 9-29.

PRECIADO, Jaime. 2008. A América Latina no sistema-mundo: questionamentos e alianças centro-periferia, in: Caderno $\mathrm{CRH}$, vol. 21, n. 53. Bahia: UFBA.

SANTOS, I.R. 2006. Conselhos de Educação e Participação Política na Semiperiferia do Sistema Mundial nos Anos: Brasil e Portugal. Dissertação (doutorado em Ciências Sociais). São Paulo: PUC/SP. 
SANTOS, Milton. 2008. Da totalidade ao lugar. 1. ed., 1. reimpr. - São Paulo: Editora da Universidade de São Paulo.

SAQUET, M. A. 2010. Abordagens e concepções de território. 2. ed. São Paulo: Expressão Popular.

SENHORAS, E. M.; VITTE, C. C. S. 2007. A agenda do desenvolvimento sob questionamento: liderança, hegemonia ou subimperialismo brasileiro na Geografia da Integração Regional da América do Sul?, in: XI Encuentro de Geógrafos de América Latina, 2007, Bogotá DC. Anais do XI Encuentro de Geógrafos de América Latina: Geopolítica, globalización y cambio ambiental: retos en el desarrollo latinoamericano. Bogotá: Unal, v. 01. p. 1-18.

SOUSA SANTOS, Boaventura. 1985. Estado e sociedade na semiperiferia do sistema mundial: o caso português, in: Análise social, vol. XXI. Lisboa: Instituto de Ciências Sociais da Universidade de Lisboa. 